\title{
Desenvolvimento da função mediadora do professor em oficinas de jogos
}

\author{
Maria Célia Rabello Malta Campos \\ Lino de Macedo
}

\begin{abstract}
Resumo
O primeiro objetivo deste artigo é descrever uma metodologia de formação docente fundamentada no conceito de Experiência de Aprendizagem Mediada descrito por Feuerstein, Klein e Tannenbaum. Seus princípios metodológicos foram adaptados ao modelo de oficinas de jogos, visando favorecer processos de aprendizagem ou formação do professor. O segundo objetivo é apresentar um estudo de caso, o da professora Juliana, em que estes aspectos são analisados com respeito aos indicadores de seus progressos como mediadora. Os dados foram extraídos de observações gravadas em vídeo efetuadas durante seu processo formativo e permitiram identificar estratégias e procedimentos que podem ser considerados como indicadores da função mediadora, de acordo com critérios de mediação definidos pelos autores citados (intencionalidadereciprocidade, transcendência e significado). O estudo pode contribuir em projetos de formação docente voltados ao desenvolvimento e avaliação de competências em métodos ativos de ensino.
\end{abstract}

Palavras-chave: Mediação da aprendizagem, formação de professores, jogos.

\section{Development of the teacher's mediation function in games workshops}

\begin{abstract}
In this study we aim at describing a method of teacher education based on Mediated Learning Experience concept, as exposed by Feuerstein, Klein e Tannenbaum. We adapted the methodological principles to games workshops model with the purpose of promoting learning processes or teacher's education. We also propose to present a case study of a 1st. grade teacher in which those aspects are analyzed by relation to some indicators of her or his progress as a mediator. The data were extracted from video record observations that took place during the teacher education process. Data allowed identifying strategies and procedures which can be considered as indicators of the mediation function, according to criteria defined by the mentioned authors. We believe this study can contribute to teacher education projects oriented to the development and assessment of competencies in active teaching methods.
\end{abstract}

Key words: Learning mediation, teacher education, games.

\section{Desarrollo de la función mediadora del profesor en talleres de juegos}

\section{Resumen}

El primer objetivo de este artículo es describir una metodología de formación docente fundamentada en el concepto de Experiencia de Aprendizaje Mediada descrito por Feuerstein, Klein y Tannenbaum. Los principios metodológicos se adaptaron al modelo de talleres de juegos, con el objetivo de favorecer procesos de aprendizaje o formación del profesor. El segundo objetivo es presentar un estudio de caso, el de la profesora Juliana, en el que estos aspectos son analizados en cuanto a los indicadores de sus progresos como mediadora. Los datos se extrajeron de observaciones grabadas en video, efectuadas durante su proceso formativo, y permitieron identificar estrategias y procedimientos que se pueden considerar como indicadores de la función mediadora, de acuerdo con criterios de mediación definidos por los autores citados (intencionalidad-reciprocidad, trascendencia y significado). El estudio puede contribuir en proyectos de formación docente dirigidos al desarrollo y evaluación de habilidades en métodos activos de enseñanza.

Palabras clave: Mediación del aprendizaje, formación de profesores, juegos. 


\section{Introdução}

Mediação é um conceito empregado em várias áreas do conhecimento e em diversos contextos de atividade. Segundo o Dicionário Eletrônico Aurélio (Ferreira, s.d.), indica uma intervenção e/ou relação promovida entre conceitos, pessoas ou coisas por meio de um terceiro termo que pode ser um conceito, uma pessoa ou uma coisa. Na Educação, mediação alude ao papel do professor na relação do aluno com o conhecimento. O professor, nesse caso, ocupa o lugar de um intermediário que apresenta os conteúdos escolares à criança de modo simultaneamente intencional e significativo. De fato, se o professor tem uma visão construtivista do ensino e aprendizagem, é melhor que suas intervenções ocorram em um contexto de mediação, conforme discutem diversos autores (Coll, 1990; Fontes, 1997; Le Boterf, 1997; Onrubia, 1998; Piaget, 1969/1972, 1974/1977; Solé \& Coll, 1998). De acordo com essa compreensão dos processos de aprendizagem, a hipótese é de que as mediações do professor potencializam, amplificam e enriquecem as construções dos alunos. Se a mediação valoriza os compromissos do professor em favor dos processos de aprendizagem, como se pode identificar uma intervenção com características ou funções mediadoras? Essa questão se apresenta para quem não deseja ficar no senso comum, apenas adotando mais um termo "da moda" pedagógica. Trata-se, verdadeiramente, de se situar diante de algo bastante abstrato e fluido, sem uma definição objetiva e comportamental. Com efeito, a palavra mediação expressa um modo relacional, com certas qualidades que expressam, basicamente, a intencionalidade de favorecer uma interação entre dois elementos (Campos, 2006). No entanto, como relação, a mediação não pode ser observada em si mesma. Ela poderá apenas ser inferida por seus indicadores, por algo que remeta a suas características e qualidades. Tornar observável, a partir de seus indícios, aquilo que constitui uma intervenção mediadora, reveste-se, assim, de importância central para o desenvolvimento da prática docente.

Embora se encontre, com certa abundância, o termo "mediação" na literatura educacional, esta carece de pesquisas que discutam os modos de expressão e as condições para o desenvolvimento da função de mediador, que tanto se valoriza no professor atualmente. Como realizar uma formação de professores, cujo foco seja o desenvolvimento de suas funções mediadoras? Nossa hipótese é de que os jogos oferecem possibilidades valiosas para o professor aprender as características de uma situação de aprendizagem mediada. Uma delas, talvez a principal, é que seu emprego em oficinas destinadas aos educadores permite retirar do contexto formativo os conteúdos pedagógicos específicos. Quando os jogos substituem os conteúdos disciplinares, consegue-se dar maior foco na forma de ação do professor, no como ele ensina, confrontando os educadores em formação com uma situação onde não é possível o ensino baseado na transmissão direta. De fato, não se ensinam diretamente as habilidades de um bom jogador. Estas não dependem apenas de um treinamento, mas resultam de construções progressivas por parte do aluno/jogador, as quais são beneficiadas por uma orientação adequada, sensível e intencional, por parte do professor. Experimentando e avaliando os resultados de suas orientações, os professores podem adquirir, aos poucos, mais segurança no emprego de intervenções que apelam para maior atividade e participação dos alunos e menor centralização de funções de sua parte, com mudanças significativas no modo de relação usualmente estabelecido em sala de aula. Aliado a isso, ao empregar jogos em sala de aula, os professores ficam mais livres para inventar, pesquisar, criar soluções, podendo até errar e tentar novamente. Isso é possível porque eles atuam e experimentam num território onde não serão cobrados por resultados da mesma forma como o seriam nas aulas regulares. Abrem-se, assim, perspectivas para que o professor possa confiar que é possível (e melhor) ensinar de outro modo, não apenas os jogos, mas qualquer conteúdo de estudo. Outro aspecto a destacar no emprego de oficinas de jogos é a condição que elas dão para se compor grupos com professores de diferentes disciplinas ou séries escolares, os quais, juntos, poderão enriquecer mutuamente suas práticas, exercitando-se na flexibilidade para a adaptação dos jogos e das intervenções ao nível dos seus alunos e de suas diferentes necessidades.

Em sua tese de doutorado, Campos (2004) analisou a importância da realização de oficinas de jogos para o desenvolvimento de competências mediadoras de professores da Escola Fundamental I. Correspondendo a um objetivo metodológico, nessa pesquisa valorizou-se a articulação entre teoria e prática para favorecer a construção de procedimentos de ensino, atitudes e formas de interação em sala de aula consoantes com a função mediadora do professor. A autora adota os pontos de vista de Le Boterf (1997), Perrenoud (1999) e Sacristàn (1998) e propõe que as competências refletem e expressam a capacidade dos professores - e dos profissionais, em geral - para articular ideias e práticas numa determinada situação, à medida que efetuam sucessivas construções acerca das coordenações e regulações ali presentes. Sendo assim, as competências definem-se em ato, no contexto em que são praticadas e em relação aos objetivos a que se destinam. Por isso, indicadores de competências são úteis para orientar a prática docente, desde que suficientemente específicos, contextualizados e objetivos. Além disso, eles devem deixar explícito seu vínculo com um quadro de referência teórica, já que nunca são neutros (Perrenoud, 1999). De acordo com essa perspectiva, um segundo objetivo do estudo consistiu na construção de indicadores das competências mediadoras, abstraídos das práticas dos participantes do projeto formativo. Para construir indicadores da função mediadora e propor uma alternativa de formação docente consoante, recorreu-se simultaneamente a duas fontes teóricas. Uma delas é a Teoria da Experiência de Aprendizagem Mediada (EAM), formulada por Reuven Feuerstein, Klein e Tannenbaum (1991). A outra fonte consistiu em resultados de pesquisas realizadas em torno do uso do jogo no contexto de ensino-aprendizagem. 
Feuerstein propõe dez critérios para qualificar uma relação mediada. Dentre eles, atribui maior relevância a três: intencionalidade/reciprocidade, transcendência e significação. A maior importância atribuída por Feuerstein a esses três critérios deve-se a que eles podem ser observados em todas as culturas, sendo assim considerados como critérios universais dessa forma de relação. Observe-se que esses aspectos são complementares, sustentando-se e enriquecendo-se mutuamente para uma efetiva mediação. A intencionalidade/reciprocidade se expressa quando o mediador busca mobilizar o mediado para a atividade e consegue compartilhar com ele um foco comum. A atividade será um mediador se o professor tiver clareza de suas finalidades e conhecimento da disciplina. Pelo lado do mediado, sua reciprocidade se expressa ao perceber o sentido da tarefa e assumi-la como sendo dele, sendo solidário numa ação intencional. A transcendência se manifesta pela ampliação do aprendido para além da experiência imediata, via representação mental e reflexão. O que é vivido com transcendência encontra-se inserido numa rede de relações, como um modelo que pode ser reutilizado em situações similares. A percepção da realidade deixa de ser fragmentada e episódica e o mediado se descobre num contexto mais integrado. A significação, por sua vez, ocorre quando as intervenções do mediador destacam as implicações de valor e as atitudes que podem estar presentes numa atividade de ensino-aprendizagem. O critério de significado traz a energia da carga afetiva aos conteúdos de aprendizagem e, para tanto, é necessário que o mediador se expresse de modo pessoal e autêntico frente a seu mediado. Os demais critérios de uma relação mediada, tais como a mediação da competência do aluno, de sua individuação e diferenciação psicológica, do controle e regulação da sua conduta, da partilha do aprendido, dependem de valores culturais e características do grupo social e podem não estar presentes em uma EAM. A Teoria da EAM orienta a metodologia do programa de desenvolvimento cognitivo ou Enriquecimento Instrumental (PEI) elaborado por Feuerstein, Rand, Hoffman e Miller (1980), em que é valorizada a atividade construtiva do aluno frente a problemas lógicos, evitando-se o treino e o ensino direto. $\mathrm{Na}$ metodologia do $\mathrm{PEI}$, as intervenções baseiam-se em perguntas e exemplos e dirigem-se, sobretudo, para o incremento da representação mental e da linguagem verbal. Por isso, ela também pode contribuir para o ensino de disciplinas curriculares e outros contextos em que a aprendizagem esteja em foco, tal como os jogos. Indicações de estratégias e diretrizes metodológicas desse programa encontram-se em Beltràn (1994), Beltràn e cols. (1994), Beyer (1996), Gomes (2002), Mentis (2000), entre outras fontes. Na proposta das oficinas de jogos, as atividades lúdicas são abordadas como uma experiência de aprendizagem mediada, sendo que a metodologia do PEI foi adaptada ao novo conteúdo, os jogos.

Para construir essa articulação entre atividades com jogos e uma prática de ensino com função mediadora, buscaram-se subsídios em pesquisas acerca do uso de jogos em sala de aula (Macedo, 1993, 2000, 2002, 2005,
2009; Macedo, Petty, \& Passos, 1997; Petty \& Passos, 1996; Ribeiro, 2001, 2005; Torres, 2001). Desse modo, empregaram-se, nas oficinas de jogos, alguns dos procedimentos metodológicos discutidos por esses autores, como a análise do processo de aprendizagem e a revisão dos erros, a problematização de fatos ou situações, a discussão e a argumentação.

Considerando os aspectos acima expostos, são dois os objetivos do presente estudo: 1) descrever uma metodologia de formação de professoras da Escola Fundamental I, a ser empregada em um contexto de supervisão, através de oficinas de jogos; 2) identificar, através de um caso, indicadores da função mediadora do professor.

\section{Descrição de uma metodologia de formação}

Número de participantes. Sugere-se que a formação seja feita em grupos pequenos de participantes (no máximo dez). Apesar disto, a diversidade nos níveis de ensino ou nas especializações dos componentes é bem-vinda.

Condições para a participação na formação. É necessário ter condição para a realização, durante, no mínimo, duas horas semanais, de atividades a serem propostas aos alunos; ter autorização dos responsáveis pelos alunos para realizar filmagens em sala de aula; e redigir relatos acerca das atividades para discuti-los nas oficinas de jogos.

Duração e periodicidade. A duração do projeto é um semestre de formação, como mínimo, em encontros quinzenais com duração de cerca de três horas cada um.

\section{Materiais e procedimentos:}

Jogos de regras ou quebra-cabeças lógicos. São considerados recursos metodológicos excelentes para permitir que professores observem processos de aprendizagem em si mesmos e em seus colegas. Tais ações oferecem oportunidade aos professores para elaboração de transcendências e construção de significados em vários níveis e sentidos.

Roteiro de análise do ato mental. Possibilita subsidiar a análise do funcionamento cognitivo dos jogadores, sejam professores ou alunos. Trata-se de adaptação do instrumento denominado Mapa Cognitivo, idealizado por Feuerstein e cols. (1980). Uma significativa parcela das atividades nas oficinas de jogos consiste em reconhecer quais aspectos explicitados no roteiro citado são postos em ação no jogo e quais estratégias podem ser usadas na orientação do processo mental dos alunos.

Textos de apoio. Visam à fundamentação teórica na metodologia proposta.

Planejamento avaliativo. Compõe-se de um esquema para o registro do planejamento semanal das atividades em sala de aula, integrado com a avaliação posterior das 
mesmas. Está baseado naquele sugerido por Beltràn (1994) para aplicadores do PEI.

Vídeos das práticas com jogos em sala de aula. São utilizados em diferentes momentos do processo formativo. A primeira, entre a primeira e a segunda sessão de supervisão, tem o objetivo de verificar como os professores lidam costumeiramente com a situação de ensino e aprendizagem em sala de aula. Com objetivo de acompanhar seus progressos, são realizadas mais duas observações gravadas. Nas sessões de supervisão, os vídeos produzidos são assistidos e comentados pelo grupo e pelo(a) formador(a).

Registros em áudio e por escrito. Subsidiam o planejamento da sequência das supervisões e a avaliação dos resultados, as gravações em áudio das entrevistas com professores participantes e das reuniões de supervisão; as anotações do(a) formador(a) em um diário; questionários escritos de perguntas abertas, como meio para avaliação parte dos participantes acerca da formação.

Estratégias de Supervisão: as coordenadas gerais que orientam a supervisão, coerentes com os princípios da experiência mediada, são as seguintes:

- Respeitar a singularidade de cada participante em relação à especificidade da sua turma de alunos, das condições de seu trabalho e das próprias possibilidades e limites, no plano pessoal. Com isso, professores têm liberdade de seguir seu próprio ritmo e podem adaptar suas intervenções conforme a realidade institucional onde atuam.

- Procurar observar, graças aos aspectos indicados no item anterior, as diferenças de ritmo, envolvimento e compreensão dos participantes e procurar atuar de acordo. Concomitantemente, procurar identificar e acompanhar as linhas gerais de desenvolvimento do grupo.

- Qualificar os professores na observação dos processos de aprendizagem de seus alunos, desse modo, contribuindo para o incremento da intencionalidade de suas intervenções.

- Adotar, como critério de progresso na formação, a autoavaliação e a expressão da tomada de consciência do professor a respeito de suas práticas de ensino, em seus pontos fortes ou deficientes.

A seguir são descritas as estratégias de formação empregadas e são indicados, resumidamente, alguns dos procedimentos direcionados à consecução dessas estratégias, consoantes, elas também, com os principais critérios da aprendizagem:

Intencionalidade-reciprocidade - Estratégias: Reconhecer as condições de trabalho das professoras na instituição e coletar dados sobre a sua prática com jogos em sala de aula. Inteirar-se da visão das coordenadoras ou diretoras em relação ao valor dos jogos para o processo de ensino-aprendizagem. Promover competências para avaliar e orientar os processos de aprendizagem dos alunos. Propiciar domínio de intervenções mediadoras no contexto dos jogos. Procedimentos: Estudo e discussão de textos de apoio. Entrevistas com a direção ou a coordenação pedagógica das escolas e com a professora. Observações gravadas da prática com jogos em sala de aula; Análise das observações gravadas. Prática dos jogos e da avaliação do próprio funcionamento ao jogar. Discussão acerca dos resultados das intervenções, com subsídio dos planejamentos avaliativos elaborados pelas professoras. Discussão e elaboração de intervenções específicas para lidar com as situações de ensino trazidas pelas professoras.

Significado - Estratégias: Promover relações entre teoria e prática. Valorização de atividades diversificadas em torno dos jogos que ofereçam contexto para a discussão coletiva, o apoio entre pares, a comunicação dos argumentos, a partilha do aprendido, entre outras atitudes relevantes ao desenvolvimento dos alunos. Procedimentos: Orientação do planejamento das atividades com jogos, com ênfase nas atividades coletivas e na comunicação verbal, como, por exemplo: jogos em equipes, duplas ou trios e incentivo ao uso de vocabulário conceitual e cognitivo, contextualizados nas atividades.

Transcendência - Estratégias: Elaborar e consolidar práticas de didática ativa. Sustentar a autonomia das professoras nas competências de mediação. Propiciar relações entre jogos e conteúdos disciplinares. Orientar a formação de critérios para seleção de atividades didáticas. Procedimentos: Orientação para pesquisas de atividades didáticas nas áreas de matemática, artes, geografia e escrita, relacionadas às noções e habilidades mobilizadas nos jogos. Organização de uma coletânea dessas atividades a partir das pesquisas das professoras. Discussão sobre as implicações de uma metodologia ativa para as práticas de ensino das participantes, suas possibilidades e limites.

\section{Indicadores da função mediadora do professor - Caso Juliana}

No tópico anterior, consideramos o primeiro objetivo deste trabalho, que consistiu na proposição de uma metodologia de formação por intermédio de oficinas de jogos. Para atender ao segundo objetivo - analisar indicadores da função mediadora do professor - apresentaremos a síntese de um caso extraído do trabalho de Campos (2004). Os observáveis aqui analisados consistem nas atitudes e nos procedimentos da professora que chamaremos de Juliana (nome fictício), considerados em relação aos critérios de mediação já citados: intencionalidade e concomitante busca da reciprocidade do aluno; transcendência dos conteúdos; significado ou valor dos mesmos. Juliana foi a professora escolhida no estudo de caso não apenas pela importância dos problemas que vivia em sala de aula, mas também porque se manteve ativa e presente durante todo o período de formação. Ela contava com onze anos de experiência docente, oito deles em classes de terceira série, em uma escola municipal no interior do Estado de São Paulo. Usava jogos em sala de aula, com finalidade recreativa e pedagógica, e sua expectativa ao participar das oficinas de jogo era melhor fundamentar esta prática. 
Para essa análise, privilegiamos os dados obtidos nas observações gravadas em sua sala de aula. Valorizamos este recurso porque permite: 1 ) descrever os procedimentos de ensino, situando-os no contexto onde a professora os exerceu; 2) inferir acerca da pertinência desses procedimentos em relação aos objetivos a que se destinavam; e 3) validar a identificação de indicadores da função mediadora do professor.

Na sequência, expomos a descrição das cenas gravadas durante as três observações em sala de aula da professora. Ao final de cada descrição, fazemos a interpretação acerca das intervenções da professora, com relação aos critérios de mediação.

Primeira observação: Contexto de apresentação aos alunos do jogo Lig-4.

Apresenta o jogo Lig-4: demonstra na lousa quadriculada como desenhar um quadrado 7x6; leva alunos a observar a estrutura do tabuleiro, questionando sobre a quantidade de espaços ou quadrados: "Quantos quadrados temos com 7 colunas e 6 fileiras?"; faz relação com conhecimentos prévios (jogo da velha) e os associa com as regras do Lig-4; desenha as direções possíveis dos alinhamentos e explicita o vocabulário espacial pertinente; chama duas crianças à lousa para jogar. Alunos observam a partida em silêncio. Ao final da partida, professora comenta o processo e alerta sobre a necessidade de se levar em conta as jogadas do adversário para fazer suas jogadas. Demonstra na lousa uma jogada vencedora: a dupla saída. Fornece aos alunos papel quadriculado como material para o jogo. Instrui para que desenhem o tabuleiro do jogo em 7 colunas e 6 fileiras. Pede que alunos se agrupem em duplas para jogar. Todos se levantam e começam a falar entre si. Há grande ruído. Um aluno passa carregando cadeira acima da cabeça e vai se sentar do outro lado da sala. Juliana aponta a demora nessa organização das duplas e cobra ordem na formação das duplas. Gesticula, indicando como as crianças devem se posicionar. Não é ouvida. Instrui sobre uso da folha para fazer várias partidas. Retoma instrução sobre o procedimento de construir quadrado $7 \times 6$ nas folhas de papel. No decorrer das partidas, percorre a sala, observando as duplas e oferecendo orientação aos jogadores. Responde dúvida de uma dupla e, em seguida, dirige-se à turma, mostrando a dúvida na lousa e orientando sobre a regra. Muitos não prestam atenção e continuam jogando. Dirige-se ao grupo mais algumas vezes, alertando para dificuldades que estavam ocorrendo, porém não recebe atenção dos alunos, muito envolvidos no jogo. Visão da sala de aula, mostrando os trabalhos da turma afixados nas paredes: há trabalhos artísticos coloridos, com uso de linhas em diferentes sentidos e vários mapas da cidade e do município. Novamente, crianças procuram Juliana com dúvidas. Ela orienta esses alunos. Crianças dialogam espontaneamente nas duplas e em pequenos grupos sobre as regras, as jogadas, os resultados das partidas. Juliana pede atenção e silêncio várias vezes. Interrompe a atividade, avisando para colocarem nome nas folhas das partidas e entregarem. Começa a re- colher o material. Pede para formar grupos de quatro alunos nos mesmos lugares, aproveitando essa organização para outra atividade. Há nova agitação na sala. Alguns alunos mudam de lugar de novo.

Comentário geral: Seus recursos para a orientação dos processos dos alunos enfraquecem-se à medida que avança na atividade. Ela prolongou o tempo das partidas em detrimento do resgate do processo com os alunos, não valorizando a socialização das dificuldades e das soluções encontradas.

Segunda observação: Contexto de resolução de situações-problema acerca do jogo Lig-4.

A uma instrução da professora, os alunos organizam-se nas duplas, virando as carteiras de frente para o colega que estava ao lado. Iniciam rapidamente as partidas. Após cerca de 10 minutos, a professora encerra as partidas e propõe a resolução de situações-problema sobre jogadas no Lig-4. Distribui folhas impressas com vários tabuleiros desenhados, com letras e números marcados nas suas bordas, formando um sistema de coordenadas na vertical e na horizontal. Os problemas solicitam uma decisão acerca das melhores jogadas a serem realizadas em um determinado momento de uma partida hipotética. Sempre em duplas, alunos marcam nos tabuleiros impressos as suas opções de jogadas; em seguida escrevem uma explicação para a resposta dada. Os alunos identificam verbalmente as posições das peças nos tabuleiros, empregando as notações de letras e números. Professora percorre a sala e interage nas duplas: observa as respostas, questiona as soluções dadas, pedindo justificativa verbal a alguns alunos. Professora permanece um período maior de tempo com uma aluna que apresenta maior dificuldade para reconhecer as possibilidades de alinhamento e encontrar as respostas; para tanto, ela emprega uma régua e a desloca aos poucos nas fileiras e colunas do tabuleiro impresso, para que a aluna identifique os espaços vazios onde poderia fazer os alinhamentos. Após 20 minutos, encerra esse trabalho em duplas e inicia a discussão das soluções dadas aos problemas. Coloca-se à frente da turma, desenha o tabuleiro na lousa e nele marca letras na horizontal e números na vertical, de forma idêntica à usada nas folhas dos alunos. A professora reproduz um problema no tabuleiro da lousa, localizando as jogadas com apoio das coordenadas. Lê as perguntas e solicita aos alunos suas respostas. As crianças participam, oferecendo suas respostas e justificando a razão.

Comentário geral: a intencionalidade da atividade consistiu em favorecer aos alunos uma representação sobre o jogo, com intervenções dirigidas para a reflexão. O emprego do tempo e do espaço expressa essa intencionalidade: 1) a introdução da proposta e a organização das duplas foram rápidas, sendo que os alunos corresponderam, mostrando condição de autonomia e organização; 2) o tempo destinado à elaboração interna, no trabalho em duplas, foi bem mais amplo, cerca de 30 minutos; 3) a mediação coletiva ocupou os 15 minutos finais da observação. Ela avaliou a diferença entre os alunos quanto à compreensão do jogo e 
orientou os alunos de acordo com sua observação, sendo flexível nos recursos empregados. A importância do respeito às diferentes opiniões e da necessidade da justificativa das respostas conferiram significado especial à atividade. Não foram registradas intervenções orientadas pelo critério da transcendência.

Terceira observação: Contexto de um desafio relacionado às estratégias do jogo TATETI.

Juliana propõe retomar o TATETI, jogo que os alunos já conheciam. Ela coloca um problema à turma: "Há um lugar melhor para se colocar ao iniciar o jogo?". Alguns respondem que a posição central do tabuleiro garante a vitória, outros discordam. Juliana pede que os alunos se agrupem em trios. Os alunos se organizam com prontidão. Ela distribui o material do jogo aos alunos (tabuleiro e seis peças, sendo três para cada jogador). Entrega também uma ficha para o registro das partidas: uma coluna para registro do nome do aluno que iniciou a partida, outra coluna para marcar qual a posição do tabuleiro por onde o jogador iniciou a partida; a terceira coluna para marcar quem ganhou o jogo. Juliana instrui os alunos sobre o registro: devem marcar a ordem das jogadas dos dois oponentes e, na coluna lateral, indicarão a colocação das fichas, com uso do código de letras e números. Indicarão também o vencedor de cada partida. Os alunos jogam e o terceiro componente do trio se encarregava dessas anotações. Há calma e ordem na classe. Observa-se que as paredes da sala estão cobertas de material de estudo: há mapas do Estado, do Brasil e do município. No mural, há mapas de ruas da cidade com legendas e itinerários marcados a cores. Após 20 minutos de início da atividade, ela encerra as partidas e passa a discutir o que encontraram. Coloca perguntas: "Quem começou colocando no ponto central, ganhou a partida? Será que há outras posições favoráveis? Ganhar a partida depende apenas do lugar na colocação inicial das peças?" Vários alunos respondem, dizendo que nem sempre a posição central garante a vitória, pois as pontas também podem favorecer o jogador. Dirige o questionamento para pensarem em outros contextos de vida: "Onde usam o que aprenderam no jogo? Como é jogar sem planejar? E onde mais se planeja? Lembram do caso do aluno que não se planejou devidamente e não conseguiu fazer o programa de lazer no clube com um amigo convidado porque que não levara a sua carteira de sócio. Juliana faz outra pergunta: "E para que serve a orientação espacial? Onde se usa?". Um aluno responde que "ajuda para não se perder". Outro aluno lembra: "Encontrar os pontos nos mapas, com as letras". Ela prossegue, indagando: "O que usamos no tabuleiro e que também está ali nos mapas? Como foi encontrar algumas cidades no mapa, sem coordenadas, e no outro mapa, com coordenadas?". Alguns alunos respondem que encontraram mais facilidade ao usarem as coordenadas.

Comentário geral: A intencionalidade se dirige para a orientação da necessidade de um comportamento metódico para coleta das informações, além de uma conduta comparativa para a análise e síntese dos dados, mediante a pre- paração de material adequado para o registro das jogadas e emprego de perguntas dirigidas à formulação e verificação de hipóteses. Expressa a mediação da transcendência ao questionar acerca das relações entre as habilidades aprendidas com o jogo e aquelas demandadas pelas situações cotidianas ou de estudo.

\section{Síntese dos indicadores da}

\section{função mediadora do professor}

A análise das observações gravadas da professora Juliana permitiu a identificação de alguns indicadores da função mediadora que sintetizamos na sequência.

Critério de Intencionalidade - Reciprocidade: Gestão do tempo, da organização do espaço e dos jogadores, da organização prévia de materiais e recursos, coerentes com os objetivos da atividade planejada. Mobilização dos alunos para a atividade e manutenção de seu interesse. Atendimento de necessidades de desenvolvimento dos alunos, contemplando suas diferenças de aprendizagem.

Critério da Transcendência: Orientação de analogias entre a atividade em sala de aula e outras dimensões da vida e do aprendizado escolar.

Critério do Significado: Organização de atividades que valorizam certas atitudes e habilidades dos alunos, como cooperação, argumentação, exercício do respeito às regras e ao colega, conduta metódica e verificação de hipóteses.

\section{Discussão}

Valoriza-se o conceito de mediação aplicado ao contexto de ensino-aprendizagem porque ele expressa uma forma de relação em que o professor orienta processos de construção de conhecimento do aluno, empregando, de modo flexível, os meios necessários para mobilizar o interesse e a ação do aprendiz, adaptando-os as suas necessidades específicas, bem como à especificidade do objeto a ser dominado. Nesse estudo, as competências na função mediadora do professor foram identificadas com apoio na Teoria da Experiência de Aprendizagem Mediada (EAM), na qual se explicitam certas qualidades indispensáveis a uma relação mediada com o conhecimento. O referencial teórico empregado possibilita a formulação de indicadores, suficientemente objetivos e explícitos, do que seja uma prática de ensino que se quer mediadora, desse modo permitindo ultrapassar os modismos e a imprecisão de conceitos que dificultam a qualificação da ação docente.

Em relação à metodologia de formação descrita, a sua hipótese orientadora, coerente com os pressupostos teóricos da mediação, é a de que ela mesma deveria servir como elemento mediador na formação continuada do professor. Trabalhou-se com a ideia de que atividades de ensino funcionam como mediadoras entre o conhecimento e 
os alunos (no caso, as professoras participantes da formação), se e quando se constituem como um problema, orientado para a construção de novos conhecimentos (Macedo, 2002; Macedo, Petty, \& Passos, 1997). Assim, no contexto das oficinas, os professores jogam e propõem os mesmos jogos a seus alunos, planejam suas estratégias e revisam os resultados de suas intervenções com a orientação da supervisão. Tendo em vista o conceito de competência profissional e, particularmente, de competência de ensino, tal como explicitado por autores como Le Boterf (1997), Perrenoud (1999), Sacristàn (1998), a formação foi organizada de modo a contribuir para ampliar a capacidade dos professores para articular suas ideias com suas práticas de ensino, de forma situada e contextualizada. Nessa mesma linha de pensamento, destaca-se a importância de os professores terem liberdade para criar recursos e organizar situações em sala de aula que pudessem expressar, na prática, os princípios centrais de uma relação mediada frente às características de seus alunos e aos problemas que emergem no ambiente da aula. A modalidade formativa proposta, enquanto mediadora, contribui para afastar os professores do modelo das "receitas prontas", que imobilizam o docente num lugar de dependência e que reforçam uma repetição mecânica e intuitiva das práticas de ensino. Ainda quanto à metodologia de formação, destacamos o duplo valor do jogo, ao mobilizar a relação entre formador e professores e destes com seus alunos. Entendemos que o jogo pode ocupar esse lugar de mediador ao possibilitar a identificação dos elementos comuns que fazem um elo entre as duas situações de ensino-aprendizagem vividas pelos professores, a supervisão em oficinas de jogos e as situações em sala de aula. Os aspectos comuns são os materiais, recursos, formas de organização, atitudes, papéis de professor e de aluno. Desse modo, o jogo serviu para promover relações entre as práticas de jogos com os alunos e as situações de ensino formal, justificando mudanças na visão do professor acerca de sua função em sala de aula.

Dada a relevância atual conferida à função mediadora do professor, procurou-se identificar um conjunto de indicadores das competências mediadoras dos processos de aprendizagem, de modo que fossem úteis em projetos de formação de professores. Nesse processo, são enfatizadas as práticas com qualidade de mediação, através de determinados aspectos que se apresentam de forma interdependente na ação docente: a intencionalidade da intervenção do professor, no sentido de obter a reciprocidade do aluno; e a transcendência, entendida como ampliação dos conteúdos aprendidos para outros contextos da experiência da criança, no tempo e no espaço, constituindo-se em aprendizagens com maior carga de significado.

Através do caso Juliana, é possível perceber-se a construção gradual dessas competências mediadoras. Verifica-se que, para exercer a mediação, é necessário que o professor faça, ele mesmo, um percurso que se inicia no clareamento e na explicitação de suas intenções e que prossegue na busca de novos (e próprios) sentidos para os fatos. Assim, os procedimentos da professora progrediram melhor e mais rapidamente em relação ao critério de intencionalidade-reciprocidade. Sendo ela docente experimentada e motivada, colocou em prática diversas estratégias que conseguiram mobilizar o envolvimento dos alunos nas atividades. Porém, em relação aos critérios de transcendência e de significado, identificou-se uma progressão mais lenta que parece ter acompanhado o processo de conscientização da professora acerca de suas funções em sala de aula, das relações com os seus alunos e com o ambiente escolar. De fato, como poderia ela animar os alunos a se perguntar sobre o sentido das situações e dos fenômenos (o porquê? O para quê?), se não o fizesse primeiro em relação a si mesma? Le Boterf, ao discutir as condições para o desenvolvimento de competências no campo profissional, aponta a necessidade do sentido da ação para o querer agir: "O profissional mobiliza suas competências em função de um projeto que comporta para ele uma significação, ao qual ele confere um sentido" (Le Boterf, 1997, p. 185). A análise do caso Juliana desvela esse processo de mobilização da professora para assumir plenamente a orientação da reflexão de seus alunos e parece indicar que fatores como tempo, oportunidade de experimentação e de reflexão são determinantes para que o profissional ganhe domínio sobre os requisitos de uma relação mediadora em uma situação complexa, tal como é a sala de aula.

\section{Considerações finais}

Descreveu-se um projeto de formação da função mediadora do professor, consistindo em encontros regulares com finalidade de supervisão para o uso de jogos em sala de aula. Procurou-se evidenciar indicadores do desenvolvimento de competências mediadoras do professor contextualizadas na orientação de competências desejadas para os alunos, tais como o domínio de técnicas, de habilidades cognitivas e de atitudes favoráveis à resolução de problemas e desafios, tanto na aprendizagem escolar como no convívio social. Desse modo, o trabalho contribui para a discussão acerca da relação entre jogos, orientação do desenvolvimento cognitivo e ensino de conteúdos escolares. Além disso, o caso apresentado permite valorizar propostas de formação docente centradas na prática da reflexão e da progressiva conscientização do professor. Nessa abordagem, as oficinas de jogos podem se constituir em alternativa valiosa para a formação do professor, dando-lhe subsídios para construir e dominar formas diferenciadas de intervenção e de relação em sala de aula no sentido da mediação. Outra decorrência do estudo consiste em fomentar interesse por outras pesquisas que possam ampliar o conhecimento acerca do emprego de observações gravadas na formação docente, dado o valor que esse recurso mostrou ter. 


\section{Referências}

Beltràn, J. M. (1994). La mediaciòn en el processo de aprendizaje. Madrid: Bruño.

Beltràn, J. M., e cols.. (1994). Metodología de la mediación en el P.E.I: orientaciones y recursos para el mediador. Madrid: Bruño.

Beyer, H. O. (1996). O fazer psicopedagógico: a abordagem de Reuven Feuerstein a partir de Piaget e Vygotsky. Porto Alegre: Editora Mediação.

Campos, M. C. R. M. (2004). Formação docente em oficinas de jogos: indicadores de mediação da aprendizagem. Tese de Doutorado, Universidade de São Paulo, São Paulo.

Campos, M. C. R. M. (2006). Mediação: faces e interfaces de uma noção complexa. Em E. Rubinstein (Org.), Psicopedagogia: fundamentos para a construção de um estilo (pp. 189-225). São Paulo: Casa do Psicólogo.

Coll, C. (1990). Un marco de referencia psicológico para la educación escolar: la concepción constructivista del aprendizaje y de la enseñanza. Em C. C. Salvador, J. Palacios, Jesus \& A. Marchesi (Orgs.), Desarrollo psicológico y educación. Psicologia de la educaciòn (Vol. 2, pp. 435-453). Madrid: Alianza.

Ferreira, A. B. de H. (s/d). Dicionário eletrônico Aurélio século XXI [CD-ROM]. Rio de Janeiro: Ed. Nova Fronteira.

Feuerstein, R., Klein, P. S., \& Tannenbaum, A. J. (Orgs.). (1991). Mediated Learning Experience (MLE): theoretical, psychosocial and learning implications. Londres: Freund Publishing House Ltd.

Feuerstein, R., Rand, Y., Hoffman, M., \& Miller, R. (1980). Instrumental Enrichment. Baltimore, MD: University Park Press.

Fontes, N. (1997). Análise de uma prática de alfabetização: estratégias de mediação numa perspectiva construtivista. Dissertação de Mestrado, Universidade Federal de São Carlos, São Carlos, São Paulo.

Gomes, C. M. de A. (2002). Feuerstein e a construção mediada do conhecimento. Porto Alegre: Artmed.

Le Boterf, G. (1997). Compétence et navigation professionale (3a ed.). Paris: Les Éditions d'Organization.

Macedo, L. (1993). Para uma psicopedagogia construtivista. Em E. S. Alencar (Org.), Novas contribuições da psicologia aos processos de ensino e aprendizagem (pp. 119-140). São Paulo: Cortez Editora.

Macedo, L. (2000). Aprender com jogos e situações-problema. Porto Alegre: Artmed.
Macedo, L. (2002). Situação-problema: forma e recurso de avaliação, desenvolvimento de competências e aprendizagem escolar. Em P. Perrenoud \& M. Thurler (Orgs.), As competências para ensinar no século XXI. A formação dos professores e o desafio da avaliação (pp. 113-135). Porto Alegre: Artmed.

Macedo, L. (2005). O lúdico nos processos do desenvolvimento e da aprendizagem escolar. Em L. Macedo, A. L. S. Petty \& N. C. Passos, Os jogos e o lúdico na aprendizagem escolar (pp. 9-22). Porto Alegre: Artmed.

Macedo, L. (2009). Teoria da equilibração e Jogo. Em L. Macedo (Org.), Jogo na Psicologia e na Educação: teoria e pesquisas (pp. 45-66). São Paulo: Casa do Psicólogo.

Macedo, L., Petty, A. L. S., \& Passos, N. C. (1997). 4 Cores, Senha e Dominó. Oficinas de jogos em uma perspectiva construtivista e psicopedagógica. São Paulo: Casa do Psicólogo.

Mentis, M. (Coord.). (2000). Aprendizagem mediada dentro e fora da sala de aula (J. F. Azevedo, Trad.). São Paulo: Instituto Pierón de Psicologia Aplicada e Ed. Senac.

Onrubia, J. (1998). Ensinar: criar zonas de desenvolvimento proximal e nelas intervir. Em C. C. Salvador, E. Martin, T. Mauri, M. Miras, J. Onrubia, I. Solé \& A. Zabala. O construtivismo na sala de aula (C. Schilling, Trad.) (pp. 123-151). São Paulo: Ática.

Perrenoud, P. (1998). La transposition didactique à partir des pratiques: des savoirs aux compétences. Em Revue des Sciences de l'Education, 24(3), pp. 487-514. Recuperado : 28 fev 2004. Disponível: http://www.unige.ch/fapse/SSE/teachers/perrenoud/ php_main/php_1998/1998_26.html.

Perrenoud, P. (1999). 10 novas competências para ensinar (P. C. Ramos, Trad.). Porto Alegre: Artmed.

Petty, A. L. S., \& Passos, N. C. (1996). Algumas reflexões sobre jogos de regras. Em F. S. Sisto (Org.), Atuação psicopedagógica e aprendizagem escolar (pp. 163-174). Petrópolis, RJ: Vozes.

Piaget, J. (1972). Psicologia e Pedagogia (D. A. Lindoso \& R. M. R. da Silva, Trad.). Rio de Janeiro: Editora Forense. (Trabalho original publicado em 1969)

Piaget, J. (1977). Prefácio. Em B. Inhelder, M. Bovet \& H. Sinclair. Aprendizagem e estruturas de conhecimento (M. A. R. Cintra \& M. Y. R. Cintra, Trad.) (pp. 7-12). São Paulo: Saraiva. (Trabalho original publicado em 1974)

Ribeiro, M. P. O. (2001). Funcionamento cognitivo de crianças com problemas de aprendizagem. Jogando e aprendendo a jogar. Tese de Doutorado, Universidade de São Paulo. São Paulo.

Ribeiro, M. P. O. (2005). Os jogos e a construção de competências na escola [Resumo]. Em Sociedade Brasileira de Psicologia do Desenvolvimento (Org.). Recuperado: 20 jan 2009. 
Disponível: <http://www.msmidia.com/sbpd/congresso/ANAIS1ConferenciaseMesasRedondas.doc $>$.

Sacristàn, G. J. (1998). Poderes instáveis em Educação (B. A. Neves, Trad.). Porto Alegre: Artmed.
Solé, I., \& Coll, C. (1998). Os professores e a concepção construtivista (C. Schilling, Trad.). Em C. C. Salvador, E. Martin, T. Mauri, M. Miras, J. Onrubia, I. Sole \& A. Zabala. O construtivismo em sala de aula (pp. 9-28). São Paulo: Ática.

Torres, M. Z. (2001). Processos de desenvolvimento e aprendizagem de adolescentes em oficinas de jogos. Tese de doutorado, Universidade de São Paulo, São Paulo.

\section{Sobre os autores}

Maria Célia Rabello Malta Campos (mc.malta@globo.com)

Pesquisadora do GT da ANPEPP: "Jogos e sua importância na Psicologia e na Educação" e do Laboratório de Psicopedagogia do Instituto de Psicologia da Universidade de São Paulo.

\section{Lino de Macedo}

Professor Titular do Instituto de Psicologia da Universidade de São Paulo.

\section{Contatos e Correspondência para:}

Maria Célia Rabello Malta Campos

Endereço: Rua Vitorino de Carvalho, 109, Vila Madalena, cep 05447-140, São Paulo, SP

Tel.: 11-3021.1483; Cel. 11- 8100.7676 